\title{
Studies on the Formation of Graft Copolymer by Coupling Reaction. II. Determination of Grafting Site of $1: 1$ Graft Copolymer by Using Star Polymers
}

\author{
Koji Ishizu, Takashi Fukutomi, and Toshio KakuraI \\ Department of Polymer Technology, Tokyo Institute of Technology, \\ Ookayama, Meguro-ku, Tokyo 152, Japan.
}

(Received May 2, 1975)

\begin{abstract}
Star polystyrenes composed of three branches (each branch was different in degree of polymerization (DP)) were synthesized, and the relationship between the elution peak count of gel-permeation chromatographs (GPC) and the DP of each branch was obtained for these star polystyrenes. Then 1:1 graft copolymer (a backbone having a single branched chain) was synthesized by the coupling reaction of polystyryl anion with chloromethylated polystyrene in tetrahydrofuran (THF) at $20^{\circ} \mathrm{C}$. The distribution of grafting sites on the backbone polymer of $1: 1$ graft copolymer was derived from the calibration of star polystyrene. It was found that polystyryl anion reacted at the part near an end pendant group of a backbone molecule; the amount reacted increased with increasing DP of polystyryl anion and with decreasing DP of backbone polymer.

KEY WORDS Degree of Polymerization / Gel-Permeation Chromatogragh / Star Polystyrene / 1:1 Graft Copolymer/Coupling Reaction / Polystyryl Anion / Chloromethylated Polystyrene / Grafting Site / Pendant Group /
\end{abstract}

In a previous paper, ${ }^{1}$ we dealt with the formation of $1: 1$ graft copolymer by the coupling reaction between poly(methyl methacrylate) (PMMA) and $\operatorname{poly}(\alpha$-methyl styryl) anion. We concluded that the structures of $1: 1$ graft copolymer were subject to changes due to the reaction conditions: i.e., the ratio of good solvent (THF) to poor solvent (methyl cyclohexane), even when the same DP of PMMA and poly( $\alpha$-methyl styryl) anion were used. Our results have shown that all pendant groups of the backbone polymer were not reacted with equal probability under various reaction conditions even at the initial stage of this reaction.

In this paper, the authors investigated the effects of the DP of the backbone and the side chain on the grafting site of $1: 1$ graft copolymer. First of all, star polystyrenes composed of three branches were synthesized, in such a way that each of the three branches had a different DP, and the relationship between the elution peak count of the GPC and the DP of each branch was obtained for these star polystyrenes. Then $1: 1$ graft copolymer was synthesized by varying the DP of the backbone molecule and the side chain. The grafting site of $1: 1$ graft copolymer was inferred from the calibration by star polystyrene.

\section{EXPERIMENTAL}

\section{Preparation of Polystyryl Anion}

Polystyryl anion was prepared by the polymerization of styrene monomer with cumyl potassium in THF. The end group of cumyl potassium was covered with small amounts of $\alpha$ methylstyrene. The molecular weight of linear polystyrene was calculated from the GPC peak. Synthesis of Star Polystyrene

Herz, et al., ${ }^{2}$ have reported that star polystyrene composed of three branches was obtained without any 2-branched polymer by coupling the polystyryl anion with tri-allyloxy-1,3,5-triazine. At the first step of the synthesis, the concentration of polystyryl anion $\left(\mathrm{DP}=P_{1}\right)$ was kept very low, compared to the concentration of tri-allyloxy-1,3,5-triazine, with the intention of forming a coupling agent having two func- 
tional groups (allyloxy groups). The reaction product was introduced into methanol and dried under vacuum after the usual purification. We used this coupling agent in the second step to synthesize the star polystyrene. Two-functional monodisperse polymeric coupling agents were reacted with the mixture of two monodisperse and monofunctional polystyryl anions $\left(\mathrm{DP}=P_{2}\right.$ and $P_{3}$ ). The reaction products are considered to be a mixture of star polystyrenes composed of $\mathrm{DP}=\left(P_{1}+2 P_{2}\right),\left(P_{1}+P_{2}+P_{3}\right)$, and $\left(P_{1}+2 P_{3}\right)$.

The synthesis procedure was as follows. Figure 1 shows this reaction apparatus. First of all, two-functional polymeric coupling agents $(\mathrm{DP}=$ $P_{1}$ ) were introduced into the reaction vessel (A) and the pressure in the system was reduced to $10^{-5} \mathrm{~mm} \mathrm{Hg}$. Then purified THF was distilled into the reaction vessel(A) and the whole apparatus was sealed off. A mixed solution of polystyryl anions $\left(\mathrm{DP}=\boldsymbol{P}_{2}\right.$ and $\left.P_{3}\right)$ was dropped into the reaction vessel (A) through the capillary with vigorous stirring. When the characteristic red color of polystyryl anion did not disappear, the reaction was complete. Then the introduction of the solution of polystyryl anion was stopped. Gel-permeation data were obtained on a Toyo Soda High Speed Liquid Chromatograph HLC801A. Measurements were made in distilled THF at $40^{\circ} \mathrm{C}$ with a mixed column having a

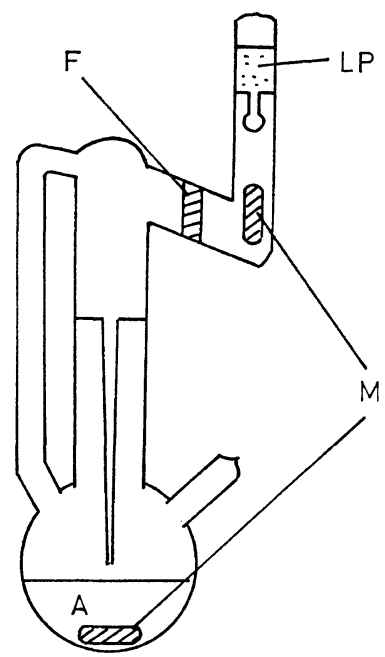

Figure 1. Apparatus to synthesize star polymer: LP, solution of polystyryl anion ( $\mathrm{DP}=P_{2}$ and $\left.P_{3}\right)$; $\mathrm{F}$, glass filter; $\mathrm{M}$, magnet coated with glass. flow rate of $1.4 \mathrm{ml} / \mathrm{min}$. The distribution function was derived from the reshaping method. ${ }^{3}$

Synthesis of 1:1 Graft Copolymer

Altares, et al., ${ }^{4}$ and Pannell ${ }^{5}$ have reported the reaction of living polymer with chloromethylated polystyrene. According to their results, the comb-shaped polystyrene was obtained in this reaction. It was often suggested that if the lithium salt of styryl anion was used as the initiator, various side reactions would occur in the coupling reaction between chloromethyl group and styryl anion, resulting in the crosslinking between parent polymers ${ }^{4,6}$. However, it was also claimed ${ }^{7}$ that such side reactions were negligible if potassium salt was used instead of lithium salt.

The polystyrene was chloromethylated ${ }^{8}$ with chloromethyl methyl ether using stannic chloride as a catalyst. The parent polymer was prepared by polymerization of styrene monomer with cumyl potassium in THF. In order to determine the chlorine content, the chloromethylated polystyrene was reacted with a large excess of sodium naphthalene in THF, and the $\mathrm{NaCl}$ salts produced were titrated by using Volhard's method $^{9}$.

The coupling reaction was done by varying the DP of the backbone and the side chain, and maintaining the concentration of polystyryl anion $\left(\mathrm{DP}=P_{1}\right)$ very low, compared to the concentration of chloromethylated polystyrene $(\mathrm{DP}=$ $P_{2}+P_{3}$ ), with the intention of forming $1: 1 \mathrm{graft}$ copolymer (solvent, THF; reaction temp, $20^{\circ} \mathrm{C}$ ). The GPC of products were obtained and were improved by the reshaping method. The GPC measurements were repeated three times. Each GPC profile thus obtained was summed and the averaged operation was carried out to cancel any observational errors.

\section{RESULTS AND DISCUSSION}

\section{Synthesis and GPC of Star Polystyrene}

The GPC profile of star polymer (SA-2) is shown in Figure 2a. The product has five peaks. Two peaks in the region of low molecular weight were GPC of two components of polystyrene $\left(\mathrm{DP}=P_{2}\right.$ and $\left.P_{3}\right)$. Therefore, the three peaks in the region of high molecular weight are considered 
K. Ishizu, T. Fukutomi, and T. Kakurai

Table Ia. Elution volume in GPC of star polystyrene

\begin{tabular}{|c|c|c|c|c|c|c|}
\hline \multirow{2}{*}{ No. } & \multirow{2}{*}{$\begin{array}{c}P_{1} \\
(\mathbf{D P})^{\mathrm{b}}\end{array}$} & \multirow{2}{*}{$\begin{array}{c}P_{2} \\
(\mathrm{DP})^{\mathrm{b}}\end{array}$} & \multirow{2}{*}{$\begin{array}{c}P_{3} \\
(\mathrm{DP})^{\mathrm{b}}\end{array}$} & \multicolumn{3}{|c|}{ Elution peak count } \\
\hline & & & & $P_{1}+2 P_{2}$ & $P_{1}+P_{2}+P_{3}$ & $P_{1}+2 P_{3}$ \\
\hline SA-1 & \multirow{4}{*}{$\begin{array}{c}1.53 \times 10^{5} \\
(1471)\end{array}$} & $\begin{array}{c}6.50 \times 10^{4} \\
(625)\end{array}$ & $\begin{array}{l}8.76 \times 10^{4} \\
(842)\end{array}$ & 24.33 & 24.47 & $-^{\mathrm{a}}$ \\
\hline SA-2 & & $\begin{array}{c}4.50 \times 10^{4} \\
(432)\end{array}$ & $\begin{array}{c}1.08 \times 10^{5} \\
(1042)\end{array}$ & 24.64 & 24.32 & 23.92 \\
\hline SA-3 & & $\begin{array}{l}2.25 \times 10^{4} \\
(216)\end{array}$ & $\begin{array}{c}1.30 \times 10^{5} \\
(1250)\end{array}$ & $-\mathrm{a}$ & 24.17 & 23.63 \\
\hline $\mathrm{SA}-4$ & & $\begin{array}{c}9.15 \times 10^{3} \\
(88)\end{array}$ & $\begin{array}{c}1.43 \times 10^{5} \\
(1379)\end{array}$ & 25.21 & 23.86 & 23.60 \\
\hline
\end{tabular}

Table Ib. Elution volume in GPC of star polystyrene

\begin{tabular}{|c|c|c|c|c|c|c|}
\hline \multirow{2}{*}{ No. } & \multirow{2}{*}{$\begin{array}{c}P_{1} \\
(\mathbf{D P})^{\mathrm{b}}\end{array}$} & \multirow{2}{*}{$\begin{array}{c}P_{2} \\
(\mathrm{DP})^{\mathrm{b}}\end{array}$} & \multirow{2}{*}{$\begin{array}{c}P_{3} \\
(\mathrm{DP})^{\mathrm{b}}\end{array}$} & \multicolumn{3}{|c|}{ Elution peak count } \\
\hline & & & & $P_{1}+2 P_{2}$ & $P_{1}+P_{2}+P_{3}$ & $P_{1}+2 P_{3}$ \\
\hline SB-1 & \multirow{4}{*}{$\begin{array}{c}1.03 \times 10^{5} \\
(987)\end{array}$} & $\begin{array}{c}6.50 \times 10^{4} \\
(625)\end{array}$ & $\begin{array}{l}8.76 \times 10^{4} \\
(842)\end{array}$ & 24.72 & 24.57 & - $^{\mathrm{a}}$ \\
\hline SB-2 & & $\begin{array}{l}4.50 \times 10^{4} \\
(432)\end{array}$ & $\begin{array}{l}1.08 \times 10^{5} \\
(1042)\end{array}$ & 24.95 & 24.45 & 24.18 \\
\hline SB-3 & & $\begin{array}{c}2.25 \times 10^{4} \\
(216)\end{array}$ & $\begin{array}{c}1.30 \times 10^{5} \\
(1250)\end{array}$ & $-^{\mathrm{a}}$ & 24.29 & 23.85 \\
\hline $\mathrm{SB}-4$ & & $\begin{array}{c}9.15 \times 10^{3} \\
(88)\end{array}$ & $\begin{array}{c}1.43 \times 10^{5} \\
(1379)\end{array}$ & 25.75 & 24.17 & 23.06 \\
\hline
\end{tabular}

Table Ic. Elution volume in GPC of star polystyrene

\begin{tabular}{|c|c|c|c|c|c|c|}
\hline \multirow{2}{*}{ No. } & \multirow{2}{*}{$\stackrel{\boldsymbol{P}_{1}}{(\mathrm{DP})^{\mathrm{b}}}$} & \multirow{2}{*}{$\begin{array}{c}P_{2} \\
(\mathrm{DP})^{\mathrm{b}}\end{array}$} & \multirow{2}{*}{$\begin{array}{c}P_{3} \\
(\mathrm{DP})^{\mathrm{b}}\end{array}$} & \multicolumn{3}{|c|}{ Elution peak count } \\
\hline & & & & $P_{1}+2 P_{2}$ & $P_{1}+P_{2}+P_{3}$ & $P_{1}+2 P_{3}$ \\
\hline $\mathrm{SC}-1$ & \multirow{4}{*}{$\begin{array}{c}2.04 \times 10^{4} \\
(196)\end{array}$} & $\begin{array}{c}6.50 \times 10^{4} \\
(625)\end{array}$ & $\begin{array}{l}8.76 \times 10^{4} \\
(842)\end{array}$ & 24.73 & 25.19 & $-a$ \\
\hline $\mathrm{SC}-2$ & & $\begin{array}{c}4.50 \times 10^{4} \\
(432)\end{array}$ & $\begin{array}{c}1.08 \times 10^{5} \\
(1042)\end{array}$ & 25.72 & 25.11 & 24.18 \\
\hline $\mathrm{SC}-3$ & & $\begin{array}{l}2.25 \times 10^{4} \\
\quad(216)\end{array}$ & $\begin{array}{c}1.30 \times 10^{5} \\
(1250)\end{array}$ & 26.41 & 25.04 & 24.16 \\
\hline $\mathrm{SC}-4$ & & $\begin{array}{c}9.15 \times 10^{3} \\
(88)\end{array}$ & $\begin{array}{c}1.43 \times 10^{5} \\
(1379)\end{array}$ & 27.81 & 24.98 & 24.15 \\
\hline
\end{tabular}

Table Id. Elution volume in GPC of star polystyrene

\begin{tabular}{|c|c|c|c|c|c|c|}
\hline \multirow{2}{*}{ No. } & \multirow{2}{*}{$\begin{array}{c}P_{1} \\
(\mathrm{DP})^{\mathrm{b}}\end{array}$} & \multirow{2}{*}{$\begin{array}{c}P_{2} \\
(\mathrm{DP})^{\mathrm{b}}\end{array}$} & \multirow{2}{*}{$\begin{array}{c}P_{3} \\
(\mathrm{DP})^{\mathrm{b}}\end{array}$} & \multicolumn{3}{|c|}{ Elution peak count } \\
\hline & & & & $P_{1}+2 P_{2}$ & $P_{1}+P_{2}+P_{3}$ & $P_{1}+2 P_{3}$ \\
\hline SD-1 & \multirow{3}{*}{$\begin{array}{l}2.04 \times 10^{4} \\
\quad(196)\end{array}$} & $\begin{array}{l}2.40 \times 10^{4} \\
(231)\end{array}$ & $\begin{array}{l}2.43 \times 10^{4} \\
\quad(234)\end{array}$ & $-\mathrm{a}$ & 27.14 & $-{ }^{a}$ \\
\hline SD-2 & & $\begin{array}{c}1.12 \times 10^{4} \\
(108)\end{array}$ & $\begin{array}{c}3.64 \times 10^{4} \\
(350)\end{array}$ & $-^{a}$ & 26.90 & 26.41 \\
\hline $\mathrm{SD}-3$ & & $\begin{array}{c}8.84 \times 10^{3} \\
(85)\end{array}$ & $\begin{array}{c}3.89 \times 10^{4} \\
(374)\end{array}$ & $-a$ & 26.84 & 26.40 \\
\hline
\end{tabular}

a The elution peak count of this star polymer could not be well resolved from the reshaped GPC.

b $\boldsymbol{P}_{\mathrm{i}}, \bar{M}_{w}$ (DP, degree of polymerization). 

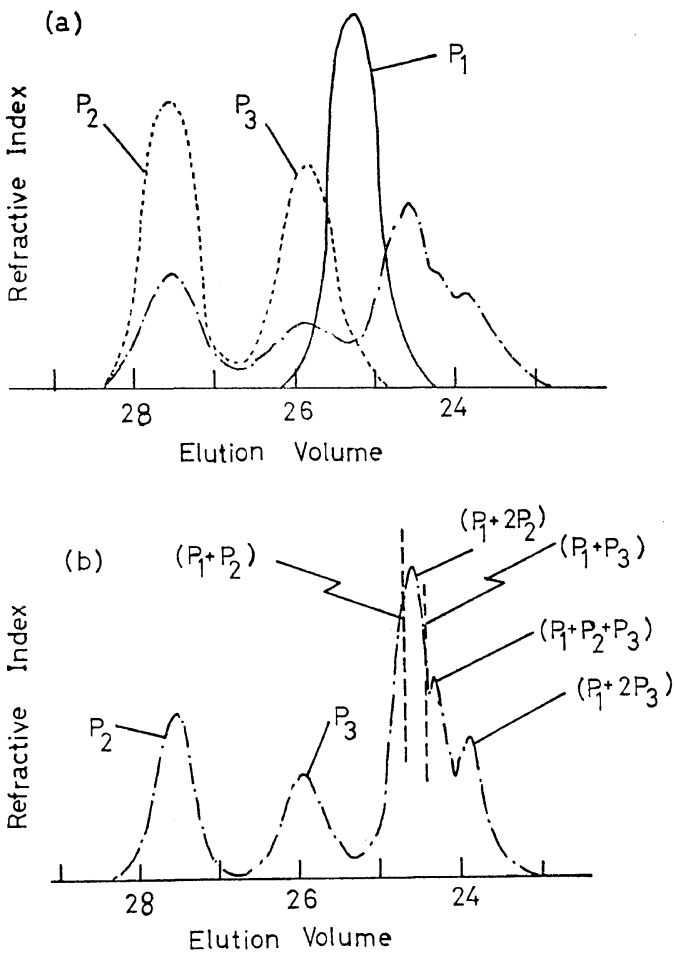

Figure 2. GPC profiles of star polystyrene (SA-2): (a) - , two-functional monodisperse polymeric coupling agents $\left(\mathrm{DP}=\boldsymbol{P}_{1}\right)$; ---, mixture of two monodisperse and monofunctional polystyryl anions $\left(\mathrm{DP}=P_{2}\right.$ and $\left.P_{3}\right) ;-.-$, reaction product; (b), reshaped GPC.

to be GPC of the mixture of star polystyrenes. Figure $2 b$ shows the reshaped GPC. The dotted lines were peak positions of linear polystyrenes having $\mathrm{DP}=\left(P_{1}+P_{2}\right)$ and $\left(P_{1}+P_{3}\right)$. The positions of the three peaks of the product did not overlap with these dotted lines. Therefore, these
GPC are star polystyrenes composed of $\mathrm{DP}=$ $\left(P_{1}+2 P_{2}\right),\left(P_{1}+P_{2}+P_{3}\right)$, and $\left(P_{1}+2 P_{3}\right)$ from left to right. Table I summarizes the relationships between the elution peak counts and the DP of star polystyrenes.

Synthesis and GPC of 1:1 Graft Copolymer

Table II shows the reaction conditions for the
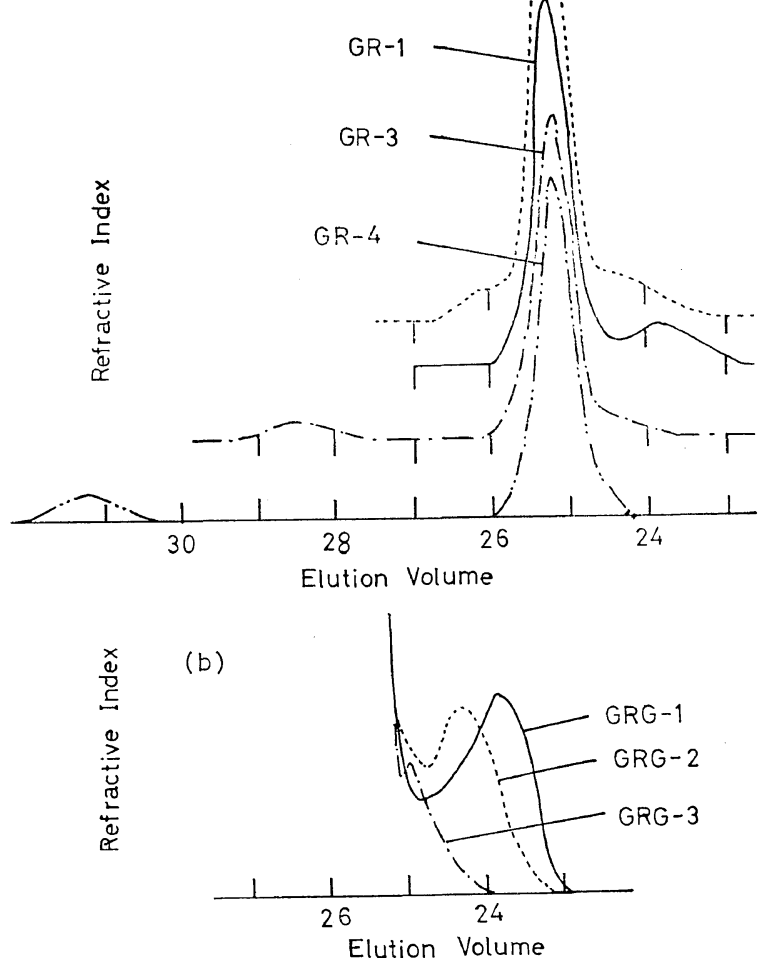

Figure 3. GPC profiles of GR-1-GR-4: (a), GPC of reaction product; (b), reshaped GPC of $1: 1 \mathrm{graft}$ copolymer.

Table II. Conditions of coupling reactions between chloromethylated polystyrene and polystyryl anion, varying the molecular weight of polystyryl anion (solvent, THF; reaction temp, $20^{\circ} \mathrm{C}$ )

\begin{tabular}{cccc}
\hline No. & $\begin{array}{c}\text { Backbone, } \\
\text { Concn } \times 10^{3}, \text { molar } \\
\text { number of molecule } / l\end{array}$ & Polystyryl anion \\
\cline { 3 - 4 } GR-1 & 2.87 & 3.5 & $\mathrm{DP}^{\mathrm{b}}$ \\
GR-2 & 3.19 & 3.8 & 1471 \\
GR-3 & 3.36 & 4.2 & 990 \\
GR-4 & 3.91 & 4.6 & 62 \\
\hline
\end{tabular}

a Chloromethylated polystyrene; $M_{n}=1.65 \times 10^{5}$ ( $\mathrm{DP}=1471$; chloromethyl groups $=250 / 1$-polymer .

b Degree of polymerization. 
Table III. Conditions of coupling reactions between chloromethylated polystyrene and polystyryl anion, varying the molecular weight of chloromethylated polystyrene

(solvent, THF; reaction temp, $20^{\circ} \mathrm{C}$ )

\begin{tabular}{ccccc}
\hline No. & \multicolumn{3}{c}{ Backbone $^{\mathrm{a}}$} & Polystyryl anion $^{\mathrm{b}}$ \\
\cline { 2 - 5 } & $\begin{array}{c}\text { Concn } \times 10^{3}, \text { molar } \\
\text { number of molecule } / l\end{array}$ & DP & $\begin{array}{c}\text { Chloromethyl groups, } \\
\text { number/1-polymer }\end{array}$ & $\begin{array}{c}\text { mol } / l \\
\text { concn }\end{array}$ \\
\hline GR-5 & 3.63 & 462 & 76 & 4.6 \\
GR-6 & 3.01 & 79 & 12 & 3.8 \\
\hline
\end{tabular}

a Chloromethylated polystyrene.

b $M_{w}=2.0 \times 10^{4}(\mathrm{DP}=192)$.

synthesis of $1: 1 \mathrm{graft}$ copolymer by varying the DP of polystyryl anion. GPC profiles of GR-1GR-4 are shown in Figure 3. The GPC peak at 25.2 count agreed with that of unreacted chloromethylated polystyrene. For GR-1-GR-3, the GPC peak shown in the region of high molecular weight (GRG) was recongized to be $1: 1$ graft copolymer from the count number and the width of the GPC. However, no GPC peak of $1: 1$ graft copolymer produced in reaction

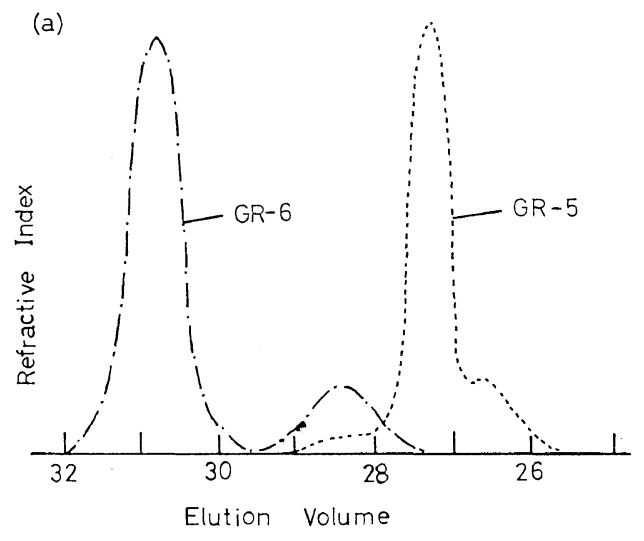

(b)

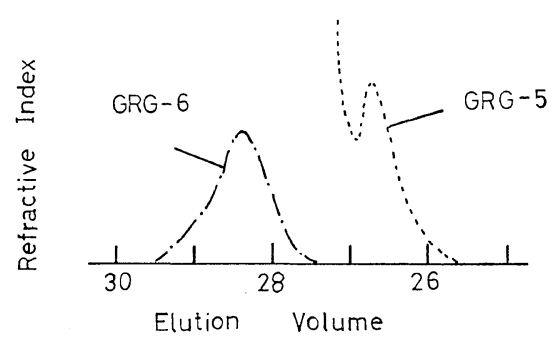

Figure 4. GPC profiles of GR-5 and GR-6: (a), GPC of reaction product; (b), reshaped GPC of 1:1 graft copolymer.
GR-4 (where the side chain length is extremely short in comparison with the backbone length) appeared. Table III shows the reaction conditions for the synthesis of 1:1 graft copolymer by varying the DP of chloromethylated polystyrene. Figure 4 shows GPC profiles of GR-5 and GR-6, and their reshaped GPC. The DP of polystyryl anion used in reactions GR-3, GR-5, and GR-6 was 192. Thus the effects of the DP of the backbone on the grafting site of $1: 1$ graft copolymer can be discussed in connection with GRG-3, GRG-5, and GRG-6.

Effects of DP of Side Chain on Grafting Sites of 1:1 Graft Copolymer

The grafting sites of GRG-1, GRG-2, and GRG-3 can be read off from the calibration of star polystyrenes: SA series (Table Ia), SB series (Table Ib), and SC series (Table Ic), respectively. Figures 5a, b, and c show the relationship between $P_{2}$ and the elution peak count of star polystyrene, for the case of changing $P_{2}$ and $P_{3}$ under the conditions of $P_{1}=$ constant and $\left(P_{2}+\right.$ $\left.P_{3}\right)=$ constant. The elution peak counts of GRG-1 23.87), GRG-2 (24.25), and GRG-3 (25.06) can be read off from Figure $3 \mathrm{~b}$. In Figure 5, the grafting sites corresponding to these values are shown by the arrows. By using the calibration curve of star polystyrene (Figure 5), the elution volumes of the reshaped GPC profiles for GRG-1, GRG-2, and GRG-3 can be transformed into $P_{2}$. The molecular weight distribution of chloromethylated polystyrene is known. Therefore, the molecular weight distributions of 1:1 graft copolymers could be separated from the two components of Figure 3b. Figure 6 shows the distribution of grafting sites of $1: 1$ graft copolymer. As a result, polystyryl anion tended to react at the part near an end pendant group 

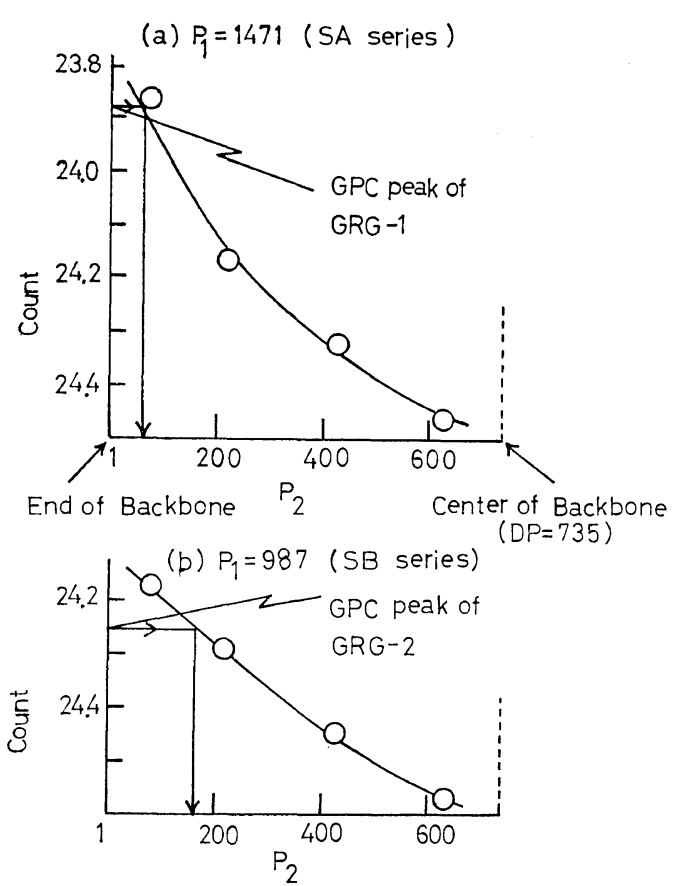

(c) $\left.P_{1}=196\right)(\mathrm{SC}$ series $)$

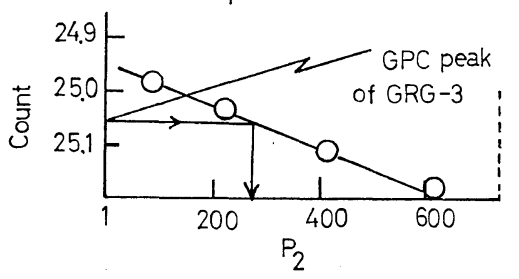

Figure 5. Relationships between elution count and $P_{2}$ for star polystyrene (SA, SB, and SC): $\bigcirc$, $\left(P_{1}+P_{2}+P_{3}\right)$.

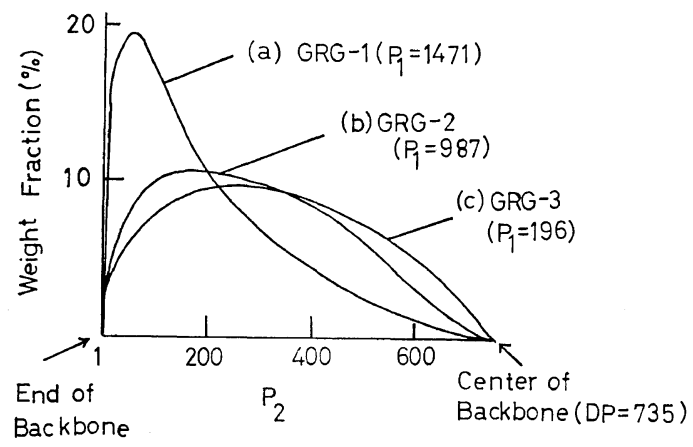

Figure 6. Distributions of grafting sites for GRG-1, GRG-2, and GRG-3. of the backbone molecule upon increasing the DP of polystyryl anion. The main factor is considered to be the intermolecular excludedvolume effects. That is to say, the center of gravity to center of gravity distance of two polymer molecules becomes far away upon increasing the DP of polystyryl anion. Therefore, the two polymer molecules become hard to overlap, and polystyryl anion reacted with the end pendant group which is located farthest away from the center of gravity of the backbone molecule ${ }^{10}$.

Effects of DP of Backbone on Grafting Site of $1: 1$ Graft Copolymer

The DP of polystyryl anion used in reactions GR-3, GR-5, and GR-6 was constant. The DP of backbone polymer for GRG-6 was 79 and the corresponding star polystyrene cannot be separated in GPC from the peaks of parent polymers. Figure 7 shows the relationship between $P_{2}$ and the elution peak count of star polystyrene (Table Id: SD series). The grafting site corresponding to the elution peak count of GRG-5 (26.80) is shown in Figure 8. 2P $2 P_{2}$ $\left(P_{2}+P_{3}\right)$ values (the degree in which the grafting

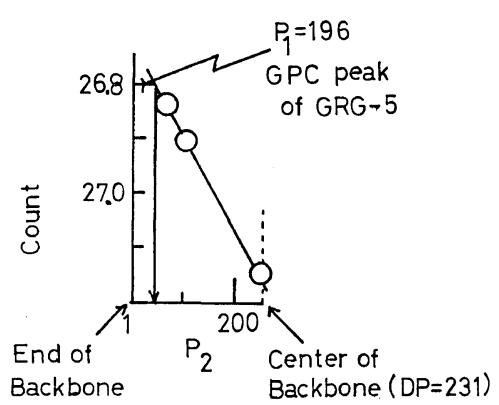

Figure 7. Relationship between elution count and $\boldsymbol{P}_{2}$ for star polystyrene (SD): $\bigcirc,\left(P_{1}+P_{2}+P_{3}\right)$.

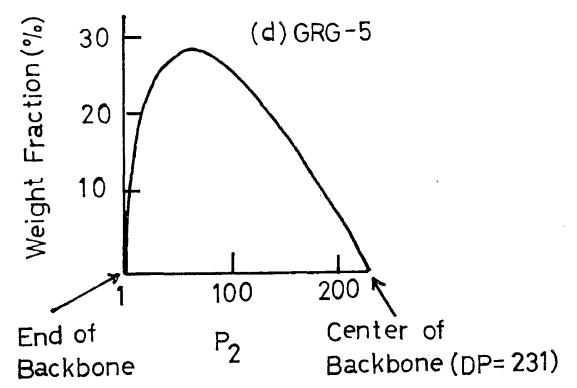

Figure 8. Distribution of grafting site for GRG-5. 
site approaches to the center from the end of a backbone molecule) of GRG-3 and GRG-5 were estimated. These results are as follows.

$$
\begin{aligned}
\text { GRG-3: } \quad 280 / 735 & =0.38 \\
\text { GRG-5: } \quad 50 / 231 & =0.21
\end{aligned}
$$

Polystyryl anion reacted at the part near an end pendant group of backbone molecule upon decreasing the DP of backbone polymer. These phenomena can be explained as follows. Upon increasing the DP of the backbone polymer, the polymer chain expands and the segment distribution tends to break away from the Gaussian. So, some pendant groups of the backbone molecule having a large DP come to locations far away from the center of gravity in comparison with those having small DP. From this paper and a previous report, ${ }^{1}$ the formation of $1: 1$ graft copolymer by coupling reaction depended strongly on the conformation of the backbone molecule and the intermolecular excludedvolume. Moreover, there is probably not a completely random reaction between the functional groups of the side chain and one end of the polymer, judging from this experimental result.

\section{REFERENCES}

1. K. Ishizu, T. Fukutomi, T. Kakurai, and T. Noguchi, Polymer J., 4, 105 (1973).

2. J. Herz, M. Hert, and C. Strazielle, Makromol. Chem., 160, 213, (1972).

3. P. E. Pierce and J. E. Armonas, J. Polym. Sci., Part C, 21, 23 (1968).

4. T. Altares, Jr., D. P. Wyman, and V. R. Allen, ibid., Part A, 3, 4131 (1965).

5. J. Pannell, Polymer, 12, 558 (1971).

6. D. F. Hoeg and D. I. Lusk, J. Amer. Chem. Soc., 86, 928 (1964).

7. S. Yen, Makromol. Chem., 81, 152 (1965).

8. G. D. Jones, Ind. Eng. Chem., 44, 2686 (1952).

9. G. Iwasaki, "Bunseki Kagaku Gaisetsu (Introduction to Quantitative Analysis)," Gakujutsutosho, Tokyo, 1963, p 276.

10. A. Ishihara, J. Phys. Soc. Japan, 5, 201 (1950). 